\title{
Escuela inclusiva: el viaje entre ayer y hoy. Una mirada interior personal para transformar la escuela
}

Enviado: 2 de junio de 2020 / Aceptado: 16 de junio de 2020

Publicado: 12 de julio de 2020

\author{
VARINIA BAUTISTA OCHOA \\ varibaumx@uma.es \\ DIANA FARZANEH PEÑA \\ 061702920x@uma.es \\ LUCÍA GONZÁLEZ LOZANO \\ 0619457669@uma.es \\ GABRIEL HERRERA POLO \\ 061071021X@uma.es
}

INMACULADA MARÍN MUÑOZ

0619440814@uma.es

INÉS MARTÍN MORENO

inesmartin66@uma.es

SANDRA MARTÍNTRUJILLO

sandratrujilli@uma.es

MARÍA SÁNCHEZ BURGOS

mariasnchezb@uma.es

ANTONIO TÉLLEZ MUÑOZ9.

tellezmunoz@uma.es

Escuela Inclusiva: Teoría y Práctica,

Universidad de Málaga, España

\section{RESUMEN}

El presente artículo muestra un antes y un después en el pensamiento sobre escuela inclusiva en el grupo de estudiantes que formaron parte del Módulo de Escuela Inclusiva: Teoría y Práctica del Máster de Políticas y Prácticas de Innovación Educativa, del curso 20192020. Se ha llevado a cabo, durante los cuatro meses
ABSTRACT

Inclusive Education: a journey between past and present. Looking into ourselves to transform the school

The following article gives a before and an after in our mindset about the Inclusive school of the group of students who are part of the Inclusive School Module: Theory and Practice of the Master's in Politics and 
de clase, una investigación basada en un grupo de discusión, el diario de clase de investigación y el análisis compartido de documentos. El objetivo de la investigación era, en primer lugar, analizar y reflexionar sobre las ideas, pensamientos y concepciones previas de cada una de las personas que integraban el Módulo, siguiendo el modelo educativo del Proyecto Roma, con la finalidad de, partiendo de esa toma de conciencia, construir en común qué es escuela inclusiva y cuáles son sus prácticas. Los resultados evidencian un cambio profundo y significativo en el pensamiento de las y los participantes, fundamentándose en multitud de estudios y lecturas que permitieron la transformación.

Palabras Clave: Formación profesional, enseñanza pública, innovación educativa, inclusión, justicia social, estudiantes.
Practices in Educational Innovation, throughout the school year 2019-2020. An investigation has been developed, during the hours shared together in class for four months, based on discussion groups, investigation classroom diaries and a shared analysis of documents and data. The investigation's aim was, at the beginning, to analyse and reflect on the previous ideas, thoughts and visions that each one of the participants that are part of the module had, following the "Proyecto Roma" methodology, with the goal of building together our own concept of Inclusive School and what should it's practice be like. The results prove a deep and significant change in the thoughts that the participants previously had, based on a wide variety of studies and documents that truly let them transform themselves.

Keywords: Vocational training, public education, educational innovations, public school, inclusion, social justice, students.

\section{A MODO DE INTRODUCCIÓN: PREPARANDO LAS MALETAS}

¡Itinerario preparado y actitud de aprendizaje activadas! Es el momento de preparar nuestro equipaje. La ilusión de llegar a ese nuevo puerto tan soñado nos une, la escuela inclusiva. Pero, ¿cuál es ese itinerario del que hablamos y quiénes nos subimos a este barco?

Somos un grupo de estudiantes universitarios del Máster de Políticas y Prácticas de Innovación Educativa conformado por docentes, en activo y aspirantes, de diferentes etapas y especialidades educativas. Nos subimos a este barco como pasajeros y de la mano de la tripulación nos convertimos en marineras y marineros que navegábamos en una misma dirección. Por tanto, somos un grupo muy heterogéneo que compartía la inquietud de seguir formándose en escuela inclusiva, unos porque ya se habían iniciado en un proceso de deconstrucción de la escuela tradicional, y otros porque sentían la necesidad de conocer otro modelo de escuela. Así pues, existen docentes en activo con un papel relevante en nuestra investigación; una de las maestras, como un faro, nos iluminaba hacia la comprensión de la escuela inclusiva desde una actitud reflexiva de su práctica, y otra docente procedente de México con gran experiencia profesional, nos acompañaba para darle otro enfoque cultural a nuestro diálogo. En definitiva, lo 
que nos unía es que entendíamos y entendemos que la docencia conlleva necesariamente un compromiso social y una actitud permanente de aprendizaje.

Se parte de una idea de escuela, que actualmente, en la mayoría de los casos no ha encontrado la manera de dar respuesta a todas las niñas y todos los niños. Se inicia esta investigación desde la situación real en la que consideramos que no existe una escuela inclusiva como tal. En las escuelas la mayor parte del alumnado comparte físicamente el mismo espacio, pero ni siquiera esto es una realidad pues siguen existiendo aulas específicas e inclusive, centros de educación especial.

El motivo por el que se ha decidido estudiar y comprender este tema, es porque el verdadero reto de la educación pública es que todo el alumnado aprenda independientemente de sus peculiaridades. Existen numerosos estudios (Ainscow, 2017; Arnáiz, 2003, 2019; Echeíta, 2017; Echeíta y Sandoval, 2002; López Melero, 2018; Sapon-Shevin, 2013; Tonucci, 2017) dedicados a este tema puesto que de la educación pública depende la ciudadanía. Se corrobora esta idea con las palabras de Ainscow (2017) que expone que esta preocupación es un foco central de la agenda 2030 para el Desarrollo Sostenible de las Naciones Unidas.

Por consiguiente, el propósito que se persigue con este trabajo es comprender qué es verdaderamente la escuela inclusiva y cuáles son los pensamientos, valores y acciones en los que se basa. Al mismo tiempo, se pretende conocer las rupturas y transformaciones por las que deben pasar las y los docentes para tomar conciencia de lo que realmente significa la educación inclusiva.

El proceso metodológico que se ha llevado a cabo para dar respuesta a los propósitos establecidos, es propio de una investigación cualitativa (Flick, 2012; Sandín, 2003), como ha sido la puesta en práctica de grupos de discusión, el análisis de documentos y la redacción de un diario de clase, el cual se constituye como un diario de investigación donde quedan reflejadas conversaciones, reflexiones y conclusiones extraídas de todo el proceso de investigación. Asimismo, se han llevado a cabo los principios y la metodología del Proyecto Roma en las clases de este Módulo, que se constituye como un modelo educativo basado en la investigación - acción.

En este artículo, en los títulos de los distintos epígrafes y sub-epígrafes se hace uso de una serie de metáforas relacionadas con esta aventura. Comienza con el epígrafe titulado "Partiendo de una ilusión", donde se profundizará en explicar el punto de vista que se tenía de la escuela inclusiva (conocimientos, lenguaje, valores, relaciones, creencias, prácticas) antes de iniciar el módulo. Se hace desde la idea de que todo lo que se exponía era la mejor forma de realizarlo para favorecer el desarrollo del alumnado. Ese mismo apartado estará dividido en cuatro epígrafes: "Un barco para todas y todos", "Echamos el ancla", "Tripulación" y "Pasajeros", donde se expone esa concepción previa de escuela, currículum, profesorado y alumnado respectivamente. 
Posteriormente, se da paso a una segunda parte titulada "De ilusionados a buscadores de verdad. Recorriendo el camino de la deconstrucción". Es en este apartado donde se narra nuestra evolución y la deconstrucción de cada uno de los sub-epígrafes anteriores, gracias al estudio bibliográfico y el grupo de discusión. De esta forma, los títulos se transforman así como lo hicieron nuestros pensamientos, y se denominan: “¿Un barco para todas y todos?”, "Levad el ancla”, "La tripulación de la mano de los pasajeros" y "Los pasajeros de la mano de la tripulación".

Siguiendo este nuevo lenguaje, la discusión y las conclusiones adquieren un nuevo matiz para denominarse: "Próximo destino: la escuela humanizada, ¿nos acompañas?". No sólo se extraen las conclusiones que hayan surgido a lo largo de este enriquecedor viaje, sino que, partiendo de la idea de que la sociedad y la escuela deben seguir evolucionando y humanizándose, os proponemos que nos acompañéis en esta aventura que no termina en este módulo.

Finalmente, se encuentran las "cartografías", todas aquellas referencias de esas marineras y marineros que han surcado estas aguas antes. Esas autoras y autores que nos han ayudado a abrir los ojos, a ver una nueva realidad.

\section{PARTIENDO DE UNA ILUSIÓN}

No sabemos lo que nos pasa y esto es precisamente lo que nos pasa.

Ortega y Gasset. 1976, p.45

Desde este barco, que es el módulo de Escuela Inclusiva: Teoría y Práctica, se habla ahora de otro barco de dimensiones mucho más amplias, tanto que debe dar cobijo a todas y todos los niños y niñas: la escuela. Se parte así de la ilusión con la que se habla de escuela inclusiva y que se mostrará a lo largo de los siguientes sub-epígrafes.

\subsection{Un barco para todas y todos}

¿Qué profesional de la educación no sueña y lucha por una escuela mejor? ¿Qué maestra o maestro no busca una escuela más inclusiva? Nadie abogaría por una escuela segregadora que excluya a las personas. Pero, la gran duda ha sido siempre ¿cómo conseguirlo? Muchos creímos que la solución estaría en la Mención de Inclusiva del Grado de Magisterio, otros hayamos información en lecturas, videos, documentales o redes sociales. Y, ¿qué encontramos? 
Para la mayoría, antes de comenzar el módulo, una escuela inclusiva era aquella en la que todo el alumnado, "normal" y "discapacitado" podía convivir unido. Además, no se le abandona a su suerte en esta escuela, sino que se acude a una herramienta reveladora que nos ayuda a comprender su realidad: el diagnóstico. Así se conocieron qué estrategias implementar con él, de forma individual y especializada, para así ofrecerle una respuesta y superar las deficiencias que le impiden alcanzar los objetivos curriculares establecidos para todo el grupo-clase.

Este alumnado puede contar con el apoyo de profesionales especialistas (de la orientación y psicología, pedagogía terapéutica y audición y lenguaje). Están la mayor parte del tiempo junto con sus compañeras y compañeros, socializando y creando vínculos, y en los casos más severos permanecerán en un aula específica con el resto de alumnas y alumnos con necesidades educativas especiales (NEE), aprendiendo cosas distintas para estimularles y alcanzar su máximo desarrollo. La Ley Orgánica 2/2006, de 3 de mayo, de Educación (LOE), con modificación en la Ley Orgánica 8/2013, de 9 de diciembre, para la Mejora de la calidad Educativa (LOMCE), recoge el derecho del alumnado con NEE a la educación inclusiva, y solo en casos muy graves se escolarizará en centros de educación especial.

Se asumía que la construcción de una escuela democrática es fundamental, con las asambleas y el voto como medio para dar voz a la comunidad. Se construyó así una idea de escuela abierta y transparente, pero en la que las decisiones siguen siendo tomadas por los profesionales de la educación.

Por lo tanto, se podría concluir, siguiendo a Stainback y Stainback (1999) que el alumnado con "discapacidad" tiene que ser aceptado desde el principio de igualdad en la comunidad educativa y recibir las adaptaciones curriculares y ayudas que precise para su aprendizaje.

\subsection{Echando el ancla}

Ese barco para todas y todos no va surcando a sus anchas, sino que echa el ancla en puerto seguro. Este ancla es el currículum de la escuela inclusiva. La atención a la diversidad es una prioridad. Se tiene en cuenta que no todo el alumnado puede acceder a los objetivos curriculares. De esta forma, se siguen unos procedimientos y medidas que ayudarán a que este alumnado con necesidades específicas de apoyo educativo acceda al currículum de la forma más justa y adecuada.

Según el Informe Warnock (1978, citado en Arnaiz, 2003) se puede modificar el currículum en mayor o menor medida, dotándolo de recursos especiales o teniendo en cuenta la estructura social y el clima emocional del aula, en función de las necesidades del alumnado.

Considerando las necesidades específicas de apoyo educativo (NEAE) que presente el alumnado, se necesita hacer una evaluación psicopedagógica que solo se debe llevar a cabo con aquel alumnado 
que presente indicios de algún tipo de dificultad o trastorno. Finalmente, tras este proceso se obtiene un diagnóstico del cual se deriva un dictamen de escolarización que define las NEE y la propuesta de modalidad de escolarización y de las ayudas que cada niña y niño precise.

Se cree que con estas adaptaciones y recursos específicos, este tipo de alumnado llegará a alcanzar el currículum ordinario, independientemente de sus limitaciones cognitivas (definidas por su coeficiente intelectual, CI), sensoriales, psicomotoras, comunicativas y lingüísticas o socioemocionales. Se utilizan así, recursos y herramientas diferentes a los libros de texto como, por ejemplo, rutinas, auto-instrucciones, profesorado "sombra”, sistemas aumentativos y alternativos de comunicación (SAAC), etc.

En definitiva, se puede resumir con el pensamiento de Arnaiz (1996) donde pone de manifiesto que en las aulas inclusivas el curriculum general se adapta cuando sea necesario para ajustarse a las necesidades del alumnado con necesidades de apoyo.

\subsection{Tripulación}

Y, lógicamente, en esa escuela inclusiva, ¿cuál es el rol del docente? Por suerte, ocurre que puede coexistir la tutora o tutor de aula junto con el profesorado especialista. Es decir, profesionales expertos en incluir al alumnado "discapacitado" que tanto preocupa. Actualmente, como docentes existe la posibilidad de especializarse en escuela inclusiva y, de esta forma, sentirse mucho más preparadas y preparados para atender a la diversidad.

El tutor o tutora impartirá el temario con las metodologías que vea más adecuadas, siempre y cuando los contenidos sean adquiridos de forma relevante. Asimismo, hay que olvidarse del docente estricto y de "mano dura", para convertirse en docentes comprensivos pero que siguen manteniendo la autoridad y el control del aula con el fin de que las clases fluyan con niveles de ruido adecuados para impartir su docencia y tampoco afectar a la labor del resto de docentes. Finalmente, se planifica y se toman decisiones de forma flexible, haciendo asambleas y teniendo en cuenta la voz del alumnado. Tal y como explica Arnaiz (2019), la función del profesorado es crucial:

Otro elemento fundamental en el desarrollo de este modelo inclusivo es el profesorado. Los estudiantes con discapacidad se benefician del profesorado que se preocupa y conoce sus características y necesidades, e incorpora en sus prácticas estrategias de adaptación curricular ligadas al diseño universal de aprendizaje favoreciendo así que el aprendizaje llegue a todos. (p. 35) 
Por último, la escuela inclusiva acepta la diversidad y la respeta y, por lo tanto, como docentes, se entiende que todo lo que se hace es para que, en la medida de sus capacidades, alcancen sus máximas posibilidades. También se trabaja de forma "especial" con el alumnado inmigrante o de etnia gitana. El profesorado es el responsable de cuidarles y apostar por todos ellos para ofrecerles una vida mejor, teniendo en cuenta la LOE, con modificación en la LOMCE, que hace referencia al principio de igualdad en educación con medidas compensatorias para las personas en riesgo de exclusión social.

\subsection{Pasajeros}

Este barco no tiene sentido sin sus pasajeros, ¿quiénes son? ¿Qué papel tienen en este viaje? Se trata del alumnado y, al igual que el profesorado, este se divide en el "ordinario" y los que presentan algunas necesidades más específicas. Pero este barco, que es la escuela inclusiva, se centra principalmente en dar respuesta a esos pasajeros con NEE, quienes se cree que son los que más lo necesitan, pues según Blanco (citado en Arnaiz, 2003) presentan dificultades para acceder al currículum por razones internas, del contexto socio-familiar o por un desajuste en el aprendizaje.

Siguiendo la teoría de Piaget, como refiere Rafael Linares (2008), el alumnado se desarrolla y aprende siguiendo una secuencia invariable y en un mismo orden, constituida por unas etapas evolutivas. Las prácticas docentes irán acordes a cómo actúa y aprende la niña o el niño en todos los estadios reforzando a través de ayuda específica para que logren superarlos. Es necesario que este tipo de alumnado reciba una atención individualizada fuera del aula ordinaria para poder dar respuesta a sus necesidades, pues al aprender con un ritmo más ralentizado o acelerado, no puede adaptarse al currículum común. De esta forma se beneficia también al resto del grupo, pues no se interrumpe el ritmo de aprendizaje general de la clase.

Como destaca Stainback y Stainback (1999) se sabe que aunque un alumno o alumna no aprenda una materia concreta se le debe incluir igualmente, pues este necesita respeto, afecto y ayuda en una sociedad integrada.

Se construye así un barco para todas y todos, con un ancla que asegura un cómodo y justo viaje, que cuenta con una tripulación preparada para satisfacer a sus pasajeros, independientemente de las necesidades que presenten y en el que, si en las aulas ordinarias hay personas que no se sienten del todo cómodas, se cuenta con camarotes especializados para que el viaje sea lo más satisfactorio posible. 


\section{DE ILUSIONADOS A BUSCADORES DE VERDAD. RECORRIENDO EL CAMINO DE LA DECONSTRUCCIÓN}

Quienes no se mueven no notan sus cadenas. Rosa Luxemburgo, citado en Weekes, 2007, p. 13

A lo largo de este viaje se ha producido un cambio en nosotras y nosotros. Sólo basta con pararse a analizar las ideas y pensamientos con los que se inició el Módulo, para darse cuenta de que ha habido una evolución hacia otras formas de ver el mundo. Para ello, se irá viendo cómo todo el discurso anterior se va desmontando conforme los pensamientos van avanzando gracias a las lecturas, reflexiones, debates, etc., que se han compartido en clase.

Recorriendo ese camino de deconstrucción de pensamientos, creencias, valores y concepciones con las que se empezó este viaje, se tomó conciencia de que se partía de una ilusión. La escuela que se creía inclusiva no lo era, parecíamos tener unas vendas que no dejaban ver. Pero el movimiento y el vaivén de este barco fomentó la búsqueda de otra verdad, desde la certeza de que no existía una verdad absoluta y que constantemente hay que buscar verdades sujetas al tiempo que resuelven situaciones problemáticas presentes.

Así, se mostrará en este apartado la evolución, cuestionamientos y reconstrucción, descubriendo una nueva escuela inclusiva. Una escuela para todas las niñas y todos los niños.

\section{1 ¿Un barco para todas y todos?}

El concepto de escuela se aprende mucho antes de ser docente, al igual que el papel docente se aprende mucho antes de serlo; "siempre se ha dicho que el profesorado no enseña tal y como le dijeron que enseñara sino como ha visto enseñar" (Imbernón, 2017, p. 54). Así, la escuela que se ha aprendido y naturalizado es una escuela donde la diversidad simplemente brilla por su ausencia. Desde luego, cada grupo humano es diverso por naturaleza y es imposible que existan grupos homogéneos; pero si el papel de la escuela es homogeneizar, termina anulando cualquier atisbo de diversidad.

En la escuela tradicional no se pudieron compartir los espacios y los tiempos con otras niñas y niños de otras culturas o etnias, con diversidad cognitiva, sexual (estaban, pero ocultas y ocultos) o funcional. Más aún, este alumnado eran personas con "discapacidad", "problemas" o "enfermos" que necesitaban una educación distinta a la mayoría, junto a buenas dosis de pena y paternalismo, porque «pobrecitas y pobrecitos», no podían hacer más. A lo sumo podrían socializarse. 
Esa es la escuela en la que construyó la identidad de muchas maestras y maestros, tanto personal como docente, pero, esa escuela se ha cuestionado y puesto en duda en numerosas ocasiones. En la formación docente inicial se aprende sobre "escuela inclusiva" y se llega a construir ese "barco para todas y todos" del que se hablaba anteriormente. Entonces, ¿por qué volver a cuestionar ese barco? Simplemente, se toma conciencia de que no era un barco para todas y todos. Era una escuela integradora, pero no inclusiva cuyo objetivo era "incluir" a aquellas y aquellos estudiantes con "discapacidad", intentando dar respuesta a lo que para la sociedad es un "déficit". Fue Sapon Shevin (2013) la que, con sus palabras, nos ilustró: "para muchos, la palabra «inclusión» significa incluir a estudiantes con discapacidad en entornos educativos tradicionales" (p. 72).

De igual forma, se fue deconstruyendo ese discurso. A través de lecturas surgían comentarios como, "me ha hecho pensar mucho que aunque el niño esté en el aula, no está incluído" o como dice Young (2012) existe una "exclusión interna". Ese apoyo de especialistas dentro o fuera del aula del que tanto se hablaba, que prometía conseguir un barco para todas y todos, ¿lo estaba consiguiendo en realidad? Las aulas específicas, las adaptaciones curriculares o cualquier medida tomada que diferenciase y etiquetase al alumnado, ¿se constituían realmente como prácticas inclusivas? Efectivamente, no. Tal y como muestran evidencias del discurso anterior, ya se estaba reflejando: "este alumnado permanece la mayor parte del tiempo junto con sus compañeras y compañeros, socializando y creando vínculos”. Eso se repetía, "socializando y creando vínculos", porque se pensaba que no podían aprender lo mismo que el resto.

Entonces, ¿qué es la escuela inclusiva? ¿Qué es un barco para todas y todos, pero con todas y todos? Ya se había aprendido que esa escuela en la que el alumnado "normal” y "discapacitado" convivía unido, no era una escuela inclusiva. Eran las palabras del faro, una compañera de clase, las que ayudaban a concretar: "la inclusión no es un beneficio únicamente para el niño peculiar, sino para que todos los demás aprendan de él también y él del resto. Al excluir al niño peculiar, privas al resto de que aprendan de él" (diario de clase). Se fue tomando conciencia de que no se ha de centrar la intervención didáctica en los sujetos, sino en cambiar los sistemas. Hablar de escuela inclusiva es hablar de justicia social y, parece lógico, que para construir una sociedad justa y honesta se deben desarrollar modelos educativos equitativos que afronten con justicia los desequilibrios existentes en la escuela (López Melero, 2019).

Así se observó a su vez que el lenguaje era el primer paso para construir la escuela que se buscaba. Se hablaba de "necesidades educativas especiales", luego de "diversidad funcional" (como si de un término más inclusivo se tratase) o de "diversidad" en relación al colectivo con "discapacidad". Sin embargo, por suerte, esas marineras y marineros que surcaron estas aguas antaño, ayudaron a concienciar de que el lenguaje configura el pensamiento. López Melero (2018), decía, "el prefijo "dis" significa Negación. No debemos decirle a nadie que, de entrada, no es capaz" (p. 3). Pero cambiar discapacidad por diversidad funcional no es suficiente y esto se hacía cada vez más evidente en los diálogos: “enton- 
ces, no es que tengamos que cambiar "discapacidad por diversidad funcional", es que directamente no deberíamos usar nada" (diario de clase). ¿Por qué usarla? Si son personas como todas las demás. Es ahí donde se encuentra la primera barrera para construir la escuela inclusiva, concebir que hay personas que aprenden y otras que aprenden menos, o de forma diferente.

La primera limitación es la incapacidad de reconocer que los niños difieren unos de otros de miles de maneras distintas y que pensar en una educación que responde y es inclusiva para un conjunto de diferencias (llamadas discapacidades) e ignorar las diferencias de raza, identidad étnica, sexo, sexualidad, idioma, religión y clase, no crea un sistema educativo realmente inclusivo para todos (Sapon Shevin, 2014, p. 72).

Cuando se usa la palabra diferencia, diversidad, peculiaridad para la otra o el otro, tenemos en el imaginario que el otro es diferente. Y el resto de personas, ¿no son peculiares? Retomando lo que escribió López Melero (2019), "la naturaleza es diversa y no hay cosa más genuina en el ser humano que la diversidad, su cualidad más humana. Y lo mismo que no hay dos amapolas iguales, no existen dos personas iguales" (p. 16).

Conforme pasaban los días, los debates eran cada vez más enriquecedores y en uno de ellos, surgió la duda: ¿y por qué llamarla escuela inclusiva? Hablar de escuela inclusiva es igual que hablar de escuela pública, pues es la que brinda esa oportunidad de que todas las niñas y los niños aprendan a descubrirse, experimentar, crear, pensar, convivir y ser en compañía de los demás. Entonces, ¿por qué se habla de dos escuelas? ¿Acaso se puede concebir una educación pública que no sea inclusiva?

Y esto, revela que en el sistema existe una dualidad. En la facultad existe la opción de formarse en escuela inclusiva, ¿y las y los estudiantes que no cursan esta mención? ¿No llevarán a cabo en el futuro prácticas inclusivas? Esa dualidad de profesorado generalista y especialista o alumnado que aprende y que no aprende, genera que se conciba que puede haber escuelas públicas inclusivas y otras que no lo son. Aunque sería más correcto hablar de que serían escuelas estatales, pero no públicas, ya que la escuela pública es la que emana de los Derechos Humanos (1948) y de los Derechos universales de la Infancia (1989).

No obstante, se cuestiona si la formación que se ofrece en la facultad sobre escuela inclusiva es, en realidad, un disfraz del modelo de escuela integradora. ¡Cómo puede ser posible que formen en escuela inclusiva si la mayor parte del profesorado habla de "necesidades educativas especiales", "discapacidad", "diversidad funcional", y enseña a diagnosticar "trastornos" siguiendo las indicaciones del DSM (Manual diagnóstico y estadístico de los trastornos mentales), un Manual elaborado para orientar a diversos profesionales desde la perspectiva clínica! ¿De verdad esto es lo que necesita la escuela pública para lograr una verdadera inclusión? ¿Esta es la formación en escuela inclusiva que se debe recibir, o es la que se quiere ofrecer? 
Por lo tanto, un barco para todas y todos, la escuela pública o común, es la escuela soñada y para la que el profesorado se debe preparar día tras día. Aquella que no solo en su discurso pretende incluir a las niñas y a los niños en sus aulas y darles un espacio físico para cohabitar, sino que también permite el desarrollo integral de todas y todos. Una escuela que se construye por quienes participan en ella, es decir, una escuela que se crea colectivamente, que permite una transformación y la justicia social. Este es el compromiso ético de la escuela pública contra la segregación y las desigualdades. Es decir, se debe pasar del principio de igualdad al principio de equidad (López Melero, 2019).

Pensar en la escuela desde las propias necesidades de una comunidad permite que, quienes participen en ella, tengan la oportunidad de tener voz y de aprender a pensar y a convivir. Se debe tener en cuenta que todas y todos tengan la posibilidad de aprender, pero que lo que se requiere son escenarios que lo permitan.

A este crear escenarios se quiere hacer especial referencia, ya que se entiende que lo que hay que cambiar no son las personas sino los contextos. El modelo inclusivo pone el foco en eso, "no se centra en que cambien los sujetos, sino en cambiar los sistemas" (López Melero, 2019, p. 4). Lo que se hace en la supuesta "escuela inclusiva" es poner el foco en el sujeto. Se centra en diagnosticar las deficiencias de la alumna o alumno con peculiaridades y se diseña todo un programa para tratar de "solventarlas" o conseguir que "desarrolle al máximo sus capacidades". Desde esta perspectiva, este alumnado, ya no sólo el que presenta algún tipo de "discapacidad", sino todo aquel que no encaja en el perfil homogéneo, que se sale de los moldes que se establecen como "normales", supone una lacra para el sistema. Sin embargo, lo que no se ve es que "la presencia de una persona con peculiaridades diferentes en cualquier contexto mejora dicho contexto, por eso debemos darle las gracias porque con su sola presencia ya nos humaniza" (López Melero, 2018, p.3).

Y, eso es lo que se busca. Un barco para todas y todos más humano, en el que se abrace la diversidad, no desde la integración sino desde una mirada más humana que reconoce en cada una las personas una peculiaridad distinta, que no ve a unos más diferentes que otros, sino que concibe a todos como humanos. Un barco en el que desaparezca la dualidad y se construya un "nosotros común" y en el que toda la comunidad tenga voz.

\section{2 ¡Levando el ancla!}

Al subirse a este barco juntas y juntos, se reflexiona también sobre otro elemento importante de la escuela, el currículum. Antes, este era el ancla del barco, la verdad sobre lo que el alumnado ha de aprender. Pero después de iniciar este viaje, revisando el cuaderno de bitácora, surgían muchas dudas. ¿Qué es el currículum? ¿Qué currículum es el que debe aportar una escuela inclusiva? 
Cuando se comenzó a reflexionar, existía una idea de currículum como una sucesión de contenidos que el alumnado tenía que memorizar y para los que no podían, simplemente se reducía para respetar sus ritmos y sus capacidades. Entonces surgía la pregunta de si este currículum era equitativo para todas las niñas y los niños. Se fue tomando conciencia de que el currículum, al igual que la escuela, distingue dos tipos de alumnado: el alumnado "ordinario" y el alumnado con "necesidades educativas especiales". Es esta diferenciación la que conduce a la exclusión. ¿Es verdaderamente inclusivo el currículum que se creía inclusivo?

Tras largas reflexiones, se llega a la conclusión de que se está ante un currículum integrador que parecía "incluir" al alumnado con peculiaridades a través de adaptaciones curriculares. Este currículum funciona como salvavidas que solo están disponibles para una parte concreta de los pasajeros del barco, y que en el mundo educativo se traduce en desigualdades porque no todas las niñas y niños pueden acceder a ellos. Además, ahora se sabe que el currículum va mucho más allá de unos contenidos culturales, pues en él debe prevalecer el desarrollo de procesos mentales de cada niña y niño, a través de la experimentación, indagación, cooperación, etc., que permitan resolver cualquier tipo de situación problemática de la vida cotidiana. Con el currículum que se creía inclusivo, no se aprende a pensar ni a convivir, siendo ésta la finalidad de la escuela pública. En este sentido, el currículum tiene que ver con la clase de ciudadanía que se desea educar. Una ciudadanía culta, reflexiva, dialogante, cooperativa, democrática, autónoma, justa y humana.

Para deconstruir la concepción que prevalecía sobre ese ancla que estancaba, también ayudaron las lecturas que llevaron a darle un giro a esa idea de currículum "inclusivo" que prevalecía. Un claro ejemplo de ello fueron las palabras de Gimeno Sacristán:

El currículum, con el sentido en el que hoy se suele concebir, tiene una capacidad o un poder inclusivo que nos permite hacer de él un instrumento esencial para hablar, discutir y contrastar nuestras visiones sobre lo que creemos que es la realidad educativa. (Gimeno Sacristán, 2010, p.11-12)

Así, el currículum se convierte en un elemento esencial pero, ¿cómo se construye un currículum que respete y valore toda la diversidad que conforma el alumnado, el profesorado, las familias y el contexto social?

Ahora se sabe que el currículum no son solo unos contenidos culturales concretos, sino que además en su construcción influyen unos intereses políticos y económicos de los gobiernos, de las editoriales o determinados grupos sociales, aunque las creencias del profesorado determinan finalmente el currículum en el aula (Beane, 2005). Los valores, creencias y concepciones del docente van a influir en gran medida en la dirección que este tome. Generalmente, llevan a segregar al alumnado, etiquetándolo de que no es capaz de aprender, cuando lo cierto es que este alumnado humaniza y enriquece el currículum. 
¿Qué nos hace pensar que la posición de las personas menos favorecidas es un mejor punto de partida para la elaboración del curriculum? Una razón bien simple es que tal posición proporciona experiencias e información de las que normalmente no disponer los grupos dominantes, quienes por consiguiente la soslayan o marginan cuando construyen el conocimiento. (Connell, 1997, pp.58-59)

Se defiende en el discurso anterior que esas medidas garantizarían la adquisición de esos contenidos y la adaptación de este alumnado, ¿pero son el diagnóstico y todas las medidas que se llevan a cabo verdaderamente inclusivas, justas y dignas? Así, surgieron varios debates en lo que se acabó tomando conciencia de lo que realmente implica un diagnóstico. Una de las compañeras comentaba lo siguiente: "La formación que he recibido durante el Grado se enfoca únicamente en detectar determinados síntomas para diagnosticar y etiquetar a los niños y niñas" (diario de clase), cuando en realidad el diagnóstico tiene que orientar sobre la modificabilidad cognitiva y cultural de las personas y no subrayar sus déficit. Como diría Freire (1997), transformar las dificultades en posibilidades. Este "click" puso de manifiesto lo que verdaderamente provocan los diagnósticos, pues no solo clasifican y etiquetan al alumnado, sino que también producen un daño y retroceso irreparable en su vida pues probablemente influya negativamente en su trayectoria escolar y relación con la sociedad.

Didácticamente hablando, esto significa decidir a priori el ofrecer a determinado alumnado una educación de menos calidad, renunciando a unas expectativas de aprendizaje al hacer una adaptación curricular, ya sea escrita o no, con lo cual, lógicamente, ni alcanzarán los mismos resultados ni se desarrollarán en función de sus peculiaridades. Se interpretan las adaptaciones curriculares como reducción del currículum, eliminando objetivos o eliminando contenidos, sin haber llevado a cabo los enriquecimientos prescriptivos de los procesos de enseñanza-aprendizaje en el aula. (López Melero, 2019, pp.8-9)

Al igual que las adaptaciones curriculares no son la solución, tampoco lo son los recursos tanto materiales como humanos que se ponen a disposición de la niña o el niño de forma individualizada, poniendo énfasis en sus peculiaridades (PT, AL, SAAC). Así, lo que se consigue es discriminar al alumnado desconectándolo del resto de sus compañeras y compañeros, no solo en los contenidos, sino también de forma física en el espacio, lo cual acaba limitando su desarrollo. Se entendió, entonces, que la labor docente no debe ser centrarse y trabajar en función de las peculiaridades que tiene esa niña o niño, sino creer en sus oportunidades modificando el contexto. Era erróneo pensar que de lo que se trataba era de cambiar a las personas cuando el verdadero cambio radica en los sistemas.

Este cambio de sistemas lleva consigo implementar metodologías y diseñar, construir y vivir contextos que apuesten por el trabajo cooperativo. Tal y como dice Slavin (1999) “el aprendizaje cooperativo aumenta el contacto entre los alumnos, les brinda una base compartida de semejanzas (la pertenencia 
a un grupo), los involucra en actividades conjuntas agradables y los hace trabajar por un objetivo común" (p. 46). De esta forma, aprenden a través del otro, entendiendo que no existe un "yo" sin un "tú" y sin un "nosotras y nosotros".

Por esto, si el educar se da en lo que es, es decir en el convivir, y no en la literatura, las conductas que los valores connotan surgen por sí mismas en su ser expresión del vivir en la armonía de lo social desde su fundamento en el amor... los valores se contagian en el vivirlos. (Maturana, 1996, p. 246)

Debido al trabajo cooperativo, las niñas y los niños aprenderán una serie de valores y formas de actuar en compañía, que se trasladará a una vida en sociedad mucho más humanizada. Siguiendo a Beane (2005) un currículum democrático implica aprender juntos, a partir de situaciones problemáticas comunes de la vida cotidiana, desde una indagación crítica.

Se hace necesario romper las amarras que constituyen un currículum tan rígido e inhumano, para crear uno en el que todas las niñas y niños tengan cabida sin ser señalados por sus peculiaridades, de manera que puedan aprender y desarrollarse de forma libre y feliz. Así pues, pasajeros y tripulantes deben levar el ancla y destruir este lastre que hunde poco a poco al barco, y así evitar un ahogo masivo tanto del profesorado como del alumnado. ¡Salvar las vidas y la educación!

\subsection{La tripulación de la mano de los pasajeros}

Se han cortado las amarras y se navega viento en popa hacia la escuela humanizada, pero aún hay mucho que cuestionar. Entre los navegantes estaba, por un lado la tripulación y, por otro, los pasajeros. Una nueva dualidad, separación y de nuevo una barrera. ¿Por qué se distancian las y los docentes del alumnado? ¿A qué tienen miedo? ¿Qué concepciones se lleva en la mochila?

En esa escuela que se llamaba "inclusiva", el profesorado se distancia del alumnado, se considera poseedor de la verdad y cree que por darle voz en determinadas situaciones ya están construyendo la democracia en el aula.

Se leía, se debatía y se reflexionaba acerca de lo que implica ser docente. Las palabras de López Melero (2019) iluminaban: "la docencia es un vivir en el compromiso permanentemente. Nuestra profesión es una actividad moral" (p. 19). Se comprendió que la profesión conlleva una responsabilidad social y moral, un compromiso con la acción. Por lo que el primer paso era plantear qué se estaba haciendo en las escuelas.

Se comienza a percibir que la existencia de un docente especialista que entrase en el aula o que sacase a niñas y niños de la misma, no era ni justo, ni humano, ni digno. ¿De qué sirve que esté dentro 
del mismo camarote, si está realizando algo totalmente distinto al resto de los tripulantes? ¿Si todos son diferentes, se necesita entonces un docente o una docente para cada persona?

Seguía el viaje y, junto a las reflexiones siempre se llegaba a la conclusión de que todo recae en la responsabilidad del profesorado, ya no sólo como docentes o futuros docentes, sino como personas, como ciudadanas y ciudadanos de un mundo que se quiere transformar. El faro volvía a alumbrar: "necesitamos profesionales que nos ayuden a ver las peculiaridades como un valor. Todos somos peculiares" (diario de clase). Y por ello, a lo largo de este viaje el objetivo era convertirse en uno de esos profesionales.

$\mathrm{Al}$ acabar las formaciones iniciales, el profesorado se siente preparado para afrontar la labor docente. Pero, ¿qué formación? ¿Una formación integradora y en algunos casos excluyente? En los diálogos se hacía patente todo lo que se ignoraba: "antes era una ignorante que ignoraba que ignoraba" (diario de clase), decía una de las compañeras. Y es verdad, como dice Ortega y Gasset (1933) y como se cita en el segundo epígrafe "no sabemos lo que nos pasa y eso es precisamente lo que nos pasa". Pero, el problema, no es que le pase al profesorado y estudiantes que han iniciado el camino hacia la búsqueda de verdades parciales. La verdadera cuestión está en que cientos de estudiantes salen cada año de las facultades con esas convicciones, con la certeza de que ayudan a "los más necesitados" y al mundo en general, cuando en realidad se divide el mundo entre los "normales" y los "deficitarios".

Pero es que la ignorancia, la falta de espíritu crítico e investigador no sólo caracterizaba al grupo de estudiantes del Módulo o a los estudiantes de educación. Las y los docentes en activo también lo sufren, porque nuestra sociedad adolece de conciencia crítica. Se volvía a comentar: "nadie se plantea cuál es el paradigma desde el que habla. No somos críticos. Yo era así porque yo no leía, me tragaba lo que me contaban. Y como decimos, lo más fácil es dejarte llevar por la corriente. Es un problema crítico e ideológico. Debemos dejar de poner el foco en los demás y ponerlo en nosotras y nosotros mismos. Está claro que tenemos un condicionamiento social. ¿Cuándo lo vamos a asumir?” (diario de clase). Es necesaria una conciencia individual y colectiva, lo que supone una lucha contra la desigualdad social y escolar y una defensa de la equidad.

Y es en este momento donde se cuestiona la cooperación. ¿Dónde queda el aprender de los demás, y que todas y todos se enriquezcan de las peculiaridades que les hacen únicos? La realidad es que se usaban los términos colaborar y cooperar como sinónimos, que se hablaba de grupos y equipos como si de lo mismo se tratase y que la convivencia, al igual que la diversidad, brilla por su ausencia. Se aprendió así a través de lecturas y debates, la diferencia entre aprendizaje colaborativo y cooperativo:

El primero es aquel que se produce cuando una persona pide ayuda a otra para poder terminar su tarea o para que le dé explicación de la misma ('me puedes ayudar, por favor). Sin embargo, el aprendizaje 
cooperativo, es aquél que se hace siempre juntos, no se pide ayuda, sino que si no se hace juntos no se puede terminar ('yo sin ti no soy nada'). (López Melero, 2019, p. 14)

Es por eso que el aprendizaje cooperativo toma un rol muy importante en una verdadera escuela inclusiva, en la escuela pública. Y ese "yo sin ti no soy nada" se pone en práctica con toda la comunidad educativa, como un todo. Es de lo que se hablaba cuando se decía que se necesitaba un "nosotros común". Se comentaba, "un nosotros común es interdependencia, es ser consciente de que no puedo construir nada sin las demás personas. Constantemente estamos tomando decisiones que perjudican al resto y no nos planteamos antes de tomar esa decisión. Implica pensar en el otro igual que piensas en ti mismo. En nuestra sociedad nadie se preocupa por la felicidad del otro" (diario de clase).

Y, por ello, de ese "sin ti no soy nada", de ese "nosotros común", surge el título de este epígrafe "la tripulación de la mano de los pasajeros". Profesorado y alumnado deben ir de la mano, se debe construir juntas y juntos la escuela soñada. Igual que se cortan las amarras del currículum hegemónico, se debe romper la jerarquía que distancia.

La tripulación de un barco para todas y todos, concibe que las niñas y los niños sin excepción, lograrán desarrollarse a partir del diálogo, la interacción y el vínculo entre lo que se aprende en la escuela y lo que se aprende en el contexto en el que viven y no a partir de la reproducción de contenidos sin sentido.

Como señala Paulo Freire (1970), “el educador ya no es solo el que educa sino aquel que, en tanto que educa, es educado a través del diálogo con el educando, quien, al ser educado, también educa" (p.72). La función docente tiene que ser aquella que acompaña el proceso de cada niña y niño, que a la vez que cumple su función de mediador del conocimiento, aprende de su alumnado desarrollándose procesos de enseñanza y aprendizaje.

Se necesita una tripulación que confíe en la potencialidad de cada uno de sus pasajeros, haciendo que esas posibilidades de aprendizaje salgan a luz con su ayuda. Además, de acuerdo con el criterio de intencionalidad/reciprocidad de Feuerstein (1990, citado en Kozulin, 2000), el fin es provocar que las niñas y niños construyan pensamiento propio. Una mediación que haga de las niñas y niños seres curiosos y críticos. Pero además, según Vygotsky (1986, citado en Kozulin, 2000) se manifestarían en ellas y ellos funciones cognitivas en proceso de desarrollo que no surgirían en solitario, dando lugar a la Zona de Desarrollo Próximo (ZDP), es decir, la diferencia entre lo que serían capaz de hacer solos y con la ayuda de los demás. 
Y todo esto no se puede llevar a cabo si no se convierten en los principios y fundamentos de la escuela pública. Fue el encuentro en clase con dos maestras del CEIP La Biznaga ${ }^{1}$ lo que ayudó a entenderlo: "sin principios ni fundamentación no se puede y también influye la ideología. Si yo no pienso que todas las niñas y niños tienen, no solo la competencia sino el derecho a educarse, no lo voy a hacer" (diario de clase).

Para lograrlo se tiene que comprender que, como explican Echeita y Sandoval (2002):

Lo que nos compete, a quienes trabajamos en y para la educación escolar, es someter a crítica los principios y las prácticas que han configurado la capacidad de generar exclusión desde el propio sistema educativo y apostar por aquellos otros que la investigación educativa y la experiencia han mostrado que promueven realmente la inclusión y la resolución pacífica de conflictos en un marco que favorece el progreso de todos los alumnos (p. 34).

Por ello, se transforma la separación entre tripulación y pasajeros y resulta necesario unirse para remar con más fuerza. Este principio de cooperación es el que une y el que ojalá una a muchos más tripulantes de otros barcos que en el futuro se unan a buscar una escuela más humana.

\subsection{Los pasajeros de la mano de la tripulación}

En el cuaderno de bitácora, las notas más importantes, las y los protagonistas de este viaje son las y los pasajeros: el alumnado.

La cultura que envuelve este barco no contempla dos tipos de pasajeros. En este navegar se deja atrás la dualidad y se empieza a mirar a los demás como humanos. Cada pasajero tiene unas peculiaridades únicas e irrepetibles, que serán apreciadas como tal y nunca infravaloradas por creencias que impidan su derecho a ser. La diversidad es lo que propicia oportunidades de aprendizaje en la escuela pública; cuanta más haya mejor aprendizaje habrá, y viceversa.

¿Y cómo logra la escuela que todo su alumnado aprenda? Conociendo cómo aprende el ser humano. Una respuesta que parece evidente, pero en la que realmente no se profundiza lo suficiente. Lo cierto es que existen varios paradigmas que lo explican.

El pensamiento más común siempre ha sido que el alumnado nace con un nivel de inteligencia en función de sus genes. Cuántas veces se ha dicho "eres igual de listo que tu padre" o "de tal palo tal

1 Se trata de una escuela pública en Málaga capital, situada en el barrio de La Mosca, conocida por ser una escuela inclusiva por la implementación del Proyecto Roma como metodología de sus prácticas. 
astilla”. En cuántas ocasiones se ha oído hablar del famoso CI. Si los docentes se parasen a reflexionar, ¿qué es realmente la inteligencia? ¿Es una propiedad intangible con la que se nace? La verdad es que el ser humano es más complejo y fascinante que todo eso. Los seres humanos vienen al mundo de manera inacabada y se acaban a través de la cultura y la educación. La inteligencia, por tanto, se construye. No depende de los genes sino de las oportunidades (López Melero, 2004).

Existen más autores que respaldan esta idea. El primero fue Vygotsky (1979), quien afirmaba que se nace con unas funciones psicológicas naturales, como la atención, percepción y memoria, que se van modificando gracias a la cultura, dando lugar a las funciones psicológicas superiores, siempre y cuando los recursos simbólicos y la mediación sean de calidad. En este sentido, a través de otros campos más actuales como la neurociencia se corrobora esta idea con autores como Eagleman (2017), quien sostiene que se nace con el cerebro inacabado, es decir, con una programación genética para funciones básicas como mamar o llorar, y que gracias a la experiencia procedente del entorno, el cerebro va creando redes neuronales hasta llegar incluso a 100 billones de conexiones a los dos años de edad. Este órgano llega a tener la capacidad de amoldarse al contexto, reforzando aquellas sinapsis que sí han sido útiles en el contexto y eliminando las que no.

Por lo tanto, no hay que esperar a que las personas lleguen a una edad que les permita desarrollarse, sino que el contexto social y cultural debe provocarlo. Se ha tomado conciencia, a lo largo del viaje, de que no es el alumnado el problema, sino los contextos. Si los docentes fuesen capaces de construir contextos adecuados, todas las niñas y niños, independientemente de sus peculiaridades y también gracias a ellas, pueden aprender.

Si se pudiera compartir esta forma de percibir la educación como la mejor herramienta para procurar la justicia social y la equidad en el mundo... Si se pudiera conmover a más docentes para que se aventuren a este viaje tan ilusionante se alcanzaría en gran medida el objetivo de esta investigación.

\section{DISCUSIÓN Y CONCLUSIONES. PRÓXIMO DESTINO: LA ESCUELA HUMANIZADA}

El viaje no termina jamás. Solo los viajeros terminan. Y también ellos pueden subsistir en memoria, en recuerdo, en narración. El objetivo de un viaje es solo el inicio de otro viaje. José Saramago, 1981

El recorrido de este viaje conlleva una serie de esfuerzos, cambios, reflexiones, debates, etc., que han dejado una huella profunda en cada una de las personas de este grupo. Este barco ha ido transfor- 
mándose conforme se ha ido viajando a distintos puertos, conociendo los elementos claves que son esenciales para seguir navegando.

¿Qué ha supuesto este nuevo concepto de escuela inclusiva? Actualmente, se cree que la escuela inclusiva va de la mano de la escuela pública, tanto que es imposible hacer distinción entre una y otra, extrayéndose así las siguientes conclusiones:

- La escuela pública es la escuela común, la de todas las niñas y todos los niños, ese es su valor, de ahí que nombrarla inclusiva resulte redundante. Se destaca aquí el primer principio para una escuela inclusiva: la idea de escuela como comunidad de convivencia y aprendizajes. En esta escuela se tiene derecho a recibir una educación y a crecer de forma libre y en compañía con los demás, es decir, se señala la escuela como modelo democrático y de inclusión social.

- La escuela se comprende como un espacio de convivencia y cooperación, donde la implicación se encuentra presente en cada una y uno de los integrantes del grupo.

- La sumersión en proyectos de investigación otorga al alumnado la autonomía, la cooperación y el desarrollo de aprendizajes.

- La escuela y el profesorado deben estar en continuo cambio, pues es la escuela el motor de transformación de la sociedad. Una escuela para todas y todas exige calidad, equidad e inclusión como ejes claves.

- La escuela para todas y todos, la común y pública, debe encontrarse en sintonía con las instituciones gubernamentales, con la participación de todos los miembros de la comunidad educativa, de proyectos educativos, que garanticen la construcción de una escuela para todas las niñas y los niños.

Estos principios se fundamentan en las investigaciones de Navareño, 2012 y López Melero, 2019.

Cuando las niñas y los niños desde pequeños aprenden a pensar, a ser reflexivos, críticos, empáticos, solidarios, investigadores, cooperativos, etc., serán personas autónomas, cultas, demócratas, inclusivas, creativas, respetuosas con los demás y su entorno, con principios morales y éticos respaldados en una argumentación sólida; y comprenderán cómo las personas actúan y son. Es decir, se convertirán en ciudadanas y ciudadanos más humanos que cambiarán el mundo en el que habitan.

En numerosos estudios se corrobora que en la verdadera escuela inclusiva solo se aprende desde la cooperación y la solidaridad mutua (Lata Doporto y Castro Rodríguez, 2016; Goikoetxea y Pascual, 2002; Johnson y Johnson, 2014; Pujolàs, 2010). Cada una y cada uno debe dar lo mejor de sí, con sus responsabilidades, sus conocimientos, sus implicaciones y ayudas al otro. En la escuela pública se 
construye un "nosotros común" que se aleja del individualismo y de la competición y que se acerca a la solidaridad y a la cooperación. Es una forma de ser en comunidad que conlleva enriquecerse unos de otros con sus propias “peculiaridades», siendo estas el valor mismo de la escuela pública.

Este viaje ha supuesto una sacudida y una ruptura de lo que eran los principios pedagógicos de este grupo. Así se crearon nuevos principios, desde la argumentación, coherentes con la escuela inclusiva. Las ideas sin acción solo son discurso.

Se comparte la idea de que las personas y las y los docentes deben actuar ante injusticias sociales, metodologías individualistas que favorezcan la segregación del alumnado, etiquetajes, políticas educativas discriminatorias, etc. Como se evidencia en la investigación de Arró, Bel, Cuartero, Gutiérrez y Peña (2004), el profesorado que posee una actitud abierta y flexible ante la diversidad, valorándose como esencia natural en todas las personas, trasladan a su práctica metodologías cooperativas que enriquecen a todo el alumnado. En este sentido, Ainscow (2001), en un artículo que hace referencia a investigaciones sobre el tema, apunta que la causa de que los centros experimenten un cambio pedagógico, ha sido una transformación en la percepción que las y los docentes tienen de su labor. Esto a su vez, provoca que, por ejemplo, su mirada hacia el alumnado con algunas peculiaridades sea otra; en vez de percibirles como un problema, consideran que estos estudiantes pueden proporcionar información valiosa sobre el funcionamiento del contexto de aula con el fin de poder mejorarlo. Por consiguiente, se debe reconocer la necesidad de transformación en el ámbito educativo, social y cultural. Se tiene la responsabilidad de hacer que la sociedad tome conciencia de la realidad para no seguir tolerando injusticias. Las palabras de José Saramago alumbran este pensamiento:

\footnotetext{
Se está preparando un mundo para los ricos... ¿Qué podemos oponerle? No tenemos poder, no estamos en el gobierno, no tenemos multinacionales, no dominamos la finanza especulativa mundial. ¿Qué es lo que tenemos para oponer? Nada más que la conciencia. La conciencia sobre los hechos, la conciencia de mi propio derecho, de que soy un ser humano y que no quiero ser más que eso; la conciencia de que lo que está en el mundo me pertenece -no en el sentido de propiedad-, me pertenece como responsabilidad, como derecho a saber, derecho a intervenir, derecho a cambiar. Eso se llama la conciencia. (Saramago, 1999).
}

Lo cierto es que este artículo ha sido el fruto de un proceso de investigación así como de planificación, con el fin de poner en práctica los principios del modelo de escuela inclusiva que se ha abordado. Por lo cual, una de las cuestiones que se quedarían pendientes tras la elaboración de esta investigación, es cómo llevarlo a cabo en la realidad de un aula en el ámbito educativo. Esta preocupación viene dada por el compromiso que conlleva la labor docente de hacer que el pensamiento, resultante de una experiencia de transformación, tenga coherencia con la acción. 
Se puede afirmar que este viaje es el inicio de un itinerario cargado de nuevas ilusiones y nuevos destinos en buena compañía. Se invita a todo el profesorado y estudiantes universitarios que comparta estos principios a unirse a esta aventura que es la construcción de la escuela humanizada.

\section{Agradecimiento}

Agradecer la labor profesional y el acompañamiento en esta investigación de Miguel López Melero, catedrático emérito de la Universidad de Málaga, concretamente en el departamento de Didáctica y Organización Escolar, director del Grupo Consolidado de Investigación HUM-246: Cultura de la Diversidad y Escuela de la Junta de Andalucía (P.A.I.) y director del Proyecto Roma. Cabe decir que se trata de un experto, de más de tres décadas, en escuela inclusiva a nivel nacional e internacional, en el que sus principales líneas de investigación son: el Proyecto Roma, la educación interculturalidad, la escuela inclusiva, la educación en valores y democracia, y la cultura de la diversidad.

Miguel es profesor del Módulo de Escuela Inclusiva: Teoría y Práctica, del Máster de Políticas y Prácticas de Innovación Educativa. Gracias por ser el puente en este proceso de aprendizaje hacia lo que somos capaces de construir y transformar. Sin su papel como mediador cultural nada de esto hubiese sido posible.

\section{CARTOGRAFÍAS}

Ainscow, M. (2001). Comprendiendo el desarrollo de escuelas inclusivas. Notas y referencias bibliográficas. Recuperado de https://www.researchgate.net/publication/266574049 COMPRENDIENDO EL DESARROLLO DE ESCUELAS INCLUSIVAS

Ainscow, M. (2017). Pasos para la inclusión en las escuelas. En EDUforics. Recuperado de http:// www.eduforics.com/es/pasos-la-inclusion-las-escuelas/

Arnaiz, P. (1996). Las escuelas son para todos. En Revista Siglo cero, 27(2), 25-34.

Arnaiz, P. (2003). Educación Inclusiva: una escuela para todos. Málaga: Ediciones Aljibe.

Arnaiz, P. (28 de enero de 2019). La educación inclusiva en el siglo XXI. Avances y desafíos. Lección magistral presentada en el Acto de Santo Tomás de Aquino, Murcia, España.

Arró Robert, M., Bel Pallarés, M. C., Cuartero Cervera, M., Gutiérrez Valverde, M., \& Peña Hernandez, P. (2004). El profesorado ante la escuela inclusiva. Jornades de Foment de la In- 
vestigació. Universitat Jaume. Recuperado de: http://repositori.uji.es/xmlui/bitstream/ handle/10234/79006/forum 2004 20.pdf? sequence=1

Bautista, V., Farzaneh, D., González, L., Herrera, G., Marín, I., Martín, I., ... Téllez, A. Diario de clase 2020. Documento no publicado.

Beane, J. (2005). La integración del currículum. El diseño del núcleo de la educación democrática. Ediciones Morata. Madrid.

Connell, R.W. (1997). Escuelas y justicia social. Madrid: Morata

Declaración de los derechos del Niño (1959). Recuperado de https://www.unicef.es/publicacion/ convencion-sobre-los-derechos-del-nino

Declaración Universal de los Derechos Humanos (1948). Recuperado de https://www.un.org/es/ universal-declaration-human-rights/

Eagleman, D. (2017). El cerebro: Nuestra historia. España: Anagrama.

Echeita, G. (2017). Educación inclusiva. Sonrisas y lágrimas. Aula Abierta, 46 (2), 17-24. https:// doi.org/10.17811/rifie.46.2017.17-24

Echeita, G. Sandoval, Marta. (2002). Educación inclusiva o educación sin exclusiones. En Revista de Educación, (327), 31- 48.

España. Ley Orgánica 2/2006, de 3 de mayo, de Educación. Boletín Oficial del Estado, 4 de mayo de 2006, núm. 106, pp. 17158-17207.

España. Ley Orgánica 8/2013, de 9 de diciembre, para la mejora de la calidad educativa. Boletín Oficial del Estado, 10 de diciembre de 2013, núm. 295, pp. 97858-97921.

Flick, U. (2012). Introducción a la investigación cualitativa. Madrid. Morata.

Freire, P. (1970). La pedagogía del oprimido. Buenos Aires: Siglo Veintiuno Editores.

Freire, P. (1997). A la sombra de este árbol. Barcelona: España; El Roure, Ed.

Gasset, J. O. Y. (1976). En torno a galileo. Revista de Occidente.

Gimeno Sacristán, J. (2010). ¿Qué significa el currículum? (adelanto). Sinéctica. Núm. 34 (2010):

Redes de comunidades académicas, Internet y educación 
Goikoetxea, E. y Pascual, G. (2002). Aprendizaje Cooperativo: Bases teóricas y hallazgos empíricos que explican su eficacia. Siglo XX1, 5, 227-247. Recuperado de http://revistas.uned. es/index.php/educacionXX1/article/view/392/342

Imbernón, F. (2017). ¿Cómo se llega a ser docente y quien los forma o deforma? En F. Imbernón. Ser docente en una sociedad compleja. La difícil tarea de enseñar (pp. 53-69). Barcelona, España: Graó.

Johnson, D. y Johnson, R. (2014). Cooperative learning in 21st century. Anales de Psicología, 30 (3), 841-851. http://dx.doi.org/10.6018/analesps.30.3.201241

Kozulin, A. (2000). Instrumentos psicológicos. La educación desde una perspectiva sociocultural. Barcelona: Paidós.

Lata Doporto, S. y Castro Rodríguez, M. (2016). El Aprendizaje Cooperativo, un camino hacia la inclusión educativa. Revista Complutense de Educación, 27 (3), 1085-1101.

López Melero M. (2018). ¿Discapacidad?, No. Personas con capacidades diferentes. Universidad de Málaga.

López Melero, M. (2004). Construyendo una escuela sin exclusiones: una forma de trabajar en el aula con proyectos de investigación. Archidona: Ediciones Aljibe.

López Melero, M. (2019). Educación Inclusiva, neoliberalismo y deshumanización de la sociedad. Conferencia I Congreso de Educación Crítica. León.

Maturana, H. (1996). El sentido de lo humano. Chile: Dolmen Ediciones.

Navareño, P. (2012). Principios para una escuela inclusiva en el siglo XXI. Avances en Supervisión Educativa, 16(6).

Pujolàs, P. (2010). Aprender juntos alumnos diferentes: los equipos de aprendizaje cooperativo en el aula. Barcelona: Ediciones Octaedro.

Rafael Linares, A. (2008). Desarrollo Cognitivo: Las Teorías de Piaget y de Vygotsky. Máster en Paidopsiquiatría. Col-legi Oficial de Psicòlegs de Catalunya. Barcelona. Universitat Autònoma de Barcelona.

Sandín, M. P (2003). Investigación Cualitativa en Educación. Fundamentos y tradiciones. Madrid: Editorial Mc Graw Hill. 
Sapon-Shevin, M. (2013). La inclusión real: una perspectiva de justicia social. Revista de Investigación en Educación, 11 (3), 71-85.

Saramago, J. (1981). Viaje a Portugal. Madrid: Alfaguara.

Saramago, J. (1999). La alternativa al Neoliberalismo se llama conciencia. Conferencia recuperada de https://youtu.be/AvBypYy EHA

Slavin, R. (1999). Aprendizaje cooperativo: Teoría, Investigación y Práctica. Buenos Aires: Aique.

Stainback, S y Stainback, W (1999). Aulas Inclusivas. Un nuevo modo de enfocar y vivir el currículo. Madrid: Narcea.

Tonucci, F. (2017). A modo de introducción...La diversidad como valor en la escuela que cambia. Aula Abierta, Volumen 46 (0), 9-12. https://doi.org/10.17811/rifie.46.2017.9-12

Vygotsky, L. S. (1979). El desarrollo de los procesos psicológicos superiores. Barcelona: Crítica.

Weekes, K. (2007). Women Know Everything!: 3,241 Quips, Quotes, \& Brilliant Remarks. Philadelphia: Quirk Books.

Young, I.M (2012). Responsabilidad por la justicia. Madrid: Morata. 